\title{
Corrigendum: Sleep and sleep disorders in rare hereditary diseases: a reminder for the pediatrician, pediatric and adult neurologist, general practitioner, and sleep specialist
}

\author{
Natan Gadoth ${ }^{1,2,3}$ * and Arie Oksenberg ${ }^{1}$ \\ 1 Sleep Disorders Unit, Loewenstein Rehabilitation Center, Raanana, Israel \\ ${ }^{2}$ Department of Neurology, Mayanei Hayeshua Medical Center, Bnei Barak, Israel \\ ${ }^{3}$ Sackler Faculty of Medicine, Tel-Aviv University, Tel-Aviv, Israel \\ *Correspondence: gadoth@post.tau.ac.il \\ Edited by: \\ David Gozal, University of Chicago, USA \\ Reviewed by: \\ Leila Kheirandish-Gozal, University of Chicago, USA
}

Keywords: Angelman, Prader-Willi, Williams-Beuren, syndrome, Chromosome Mapping

\section{A corrigendum on}

Sleep and sleep disorders in rare hereditary diseases: a reminder for the pediatrician, pediatric and adult neurologist, general practitioner, and sleep specialist by Gadoth N, Oksenberg A. Front Neurol (2014) 5:133. doi:10.3389/fneur.2014. 00133

A corrigendum on Angelman, Prader Willi and Williams-Beuren Syndromes (Page 5)
Angelman and Williams Beuren syndromes are not autosomal recessive (AR) and Prader-Willi syndrome is not autosomal dominant as incorrectly stated in the text.The rest of the molecular genetic information given is correct. We apologies for the inconvenience.

Conflict of Interest Statement: The authors declare that the research was conducted in the absence of any commercial or financial relationships that could be construed as a potential conflict of interest.

Received: 08 January 2015; accepted: 10 January 2015; published online: 26 January 2015.
Citation: Gadoth N and Oksenberg A (2015) Corrigendum: Sleep and sleep disorders in rare hereditary diseases: a reminder for the pediatrician, pediatric and adult neurologist, general practitioner, and sleep specialist. Front. Neurol. 6:6. doi: 10.3389/fneur.2015.00006

This article was submitted to Sleep and Chronobiology, a section of the journal Frontiers in Neurology. Copyright () 2015 Gadoth and Oksenberg. This is an open-access article distributed under the terms of the Creative Commons Attribution License (CC BY). The use, distribution or reproduction in other forums is permitted, provided the original author(s) or licensor are credited and that the original publication in this journal is cited, in accordance with accepted academic practice. No use, distribution or reproduction is permitted which does not comply with these terms. 